\title{
An Investigation of Big Five and Narrow Personality Traits in Relation to Learner Self-Direction in Undergraduate Students
}

\author{
Jeral Kirwan ${ }^{1, *}$ \\ ${ }^{1}$ Department of Educational Psyhology and Research, The University of Tennessee, Knoxville TN, USA \\ *Correspondence: 8200 E. 8th Ave \#4-104, Denver, CO 80230, USA. Tel: 1-865-973-1533. E-mail: \\ jkirwan@utk.edu
}

Received: March 5, 2014

Accepted: March 18, $2014 \quad$ Online Published: April 14, 2014

doi:10.5430/jct.v3n1p74

URL: http://dx.doi.org/10.5430/jct.v3n1p74

\begin{abstract}
Self-direction in learning is a major topic in the field of adult learning. There has been extensive coverage of the topic by theorists, researchers, and practitioners. However, there have been few studies which look at learner self-direction specifically as a personality trait. The present study addresses the relationship between learner self-direction and other personality traits of college students when the traits represented by the five-factor model of personality (Digman, 1990) are differentiated from narrow personality traits. Archival data were used from an undergraduate sample at a large Southeastern U.S. university (sample size $=1981$ ). Correlation and multiple regression analyses were used in examining the unique individual relationship between Big Five and narrow personality traits and learner self-direction. Analysis of the data revealed five significant part correlations between specific traits and learner self-direction. The part correlations for Work Drive (.30), Openness (.19), and Optimism (.12) were significantly higher than all other part correlations. Neither Conscientiousness nor Agreeableness had significant part correlations despite having significant zero-order correlations with learner self-direction. Extraversion did not have a significant zero-order correlation with learner self-direction but the part correlation was significant. Results were discussed in terms of the predictive relationship between personality variables and learner self-direction. Study implications, some limitations, and possible directions for future research were noted.
\end{abstract}

Keywords: personality; the Big Five theory; adult learning; learner self-direction

\section{Introduction}

Self-direction in learning is a major topic in the field of adult learning. There has been extensive coverage of the topic by theorists, researchers, and practitioners (e.g., Brockett \& Hiemstra, 1991; Long \& Redding, 1991). Long (2007) has identified several themes and measurements of self-direction in learning that have focused on psychological factors. Several empirical measures have been developed to measure different dimensions of self-direction in learning that address psychological factors such as the Self-Directed Learning Readiness Scale (SDLRS) (Guglielmino, 1977), the Oddi Continuing Learning Inventory (OCLI) (Oddi, 1984), and more recently the Personal Responsibility Orientation to Self-Direction in Learning Scale (PRO-SDLS)(Stockdale \& Brockett, 2011). It has been shown that many psychological variables are directly related to learner self-directedness (Oliveira \& Simões, 2006). However, there have been few studies that look at learner self-direction specifically as a personality trait. If personality traits are relatively consistent for learners across situations and over time, and if learner self-direction changes across situations and over time, the most logical interpretation of why the personality trait-learner self-direction relationship is relatively consistent within and across such disparate factors as age and returning to college after a long break is because the personality traits are driving the relationship. This implies that other personality traits are affecting learner self-direction, not that learner self-direction is influencing other personality traits.

The purpose of the present study is to try to understand the connection between personality and self-direction in learning and ascertain to what extent individual personality traits are related to learner self-direction when the traits represented by the five-factor model of personality (Digman, 1990) are differentiated from narrow personality traits. This study is directly based on and extends the work of Lounsbury, Levy, Park, Gibson, and Smith (2009) and 
Kirwan, Lounsbury, and Gibson (2010). The present study differs from the previous two studies in that it examines the unique relationship of individual traits to learner self-direction and their relative importance in accounting for variation in learner self-direction.

\subsection{Statement of the Problem}

In order to explicate the connection between personality and self-direction in learning, it is important to understand that personality traits are relatively stable. On the other hand, self-directed learning is situational and can vary over time. Therefore, the question addressed here can be phrased as what is the unique relationship between specific personality traits and learner self-direction?

It has been shown that many psychological variables, such as Conscientiousness, are directly related to learner self-directedness (Oliveira \& Simões, 2006). However, there have been few studies that look at learner self-direction specifically as a personality trait. If personality traits are relatively consistent for learners across situations and over time, and if learner self-direction changes across situations and over time, the most logical interpretation of why the personality trait-learner self-direction relationship is relatively consistent within and across such disparate factors as age and returning to college after a long break is because the personality traits are driving the relationship. This implies that other personality traits are affecting learner self-direction, not that learner self-direction is influencing other personality traits. The goal of the present study is to try to understand the connection between personality and self-direction in learning and ascertain to what extent individual personality traits are related to learner self-direction.

\subsection{Relevant Scholarship}

In the current investigation, the focus is on a person's learner self-direction as an individual differences variable which can be represented on a continuum from low to high. Brockett and Hiemstra's (1991) proposed a two-dimension model where one dimension is learner self-direction. With respect to Brockett and Hiemstra's (1991) two-dimension, self-direction in learning model, the learner self-direction construct used in this study corresponds to their learner self-direction construct as "characteristics of an individual that predispose one toward taking primary responsibility for personal learning endeavors" (p. 29). Consistent with prior conceptualizations of self-direction in learning (e.g., Brockett, 1983; Brockett \& Hiemstra, 1991; Costa \& Kalick, 2003), learner self-direction was conceptualized and measured as a personality trait reflecting an individual's preference to be in charge of their learning process; ability to conceptualize, plan, implement, and evaluate their academic experience; and disposition to be goal-oriented and to work independently or in group settings with little guidance.

Relationships between personality and learner self-direction among college students were chosen for several reasons. The college experience is regarded as providing "many opportunities for students to develop, among other things, personal and professional identity" (Hamrick, Evans, \& Schuh, 2002, p.135). As Madison (1969) observed, college represents a unique and highly appropriate setting for studying aspects of personality such as identity and learning style. Moreover, for those individuals who go to college directly from high school, the college experience occurs during a key developmental period for identity development (Waterman, 1985, 1993), and it is regarded as playing a "critical role in identity formation" (Nakula, 2003, p.9).

In the rationale for their study, Lounsbury et al. (2009) made three important observations: (1) personality traits may influence or provide the foundation for self-direction in learning-development processes (p. 412); (2) when considered as a whole, much of the prior literature on the relationship between self-direction in learning and personality traits (Johnson, Sample, \& Jones, 1988; Leitsch \& Van Hove, 1998) is lacking in continuity; and (3) the Big Five model of personality represents an "organizing scheme" for understanding self-direction in learning-personality trait relations. With regard to the latter point, the Big Five model of personality traits of Openness, Conscientiousness, Extraversion, Agreeableness, and Neuroticism (which will referred to here by its inverse-Emotional Stability) is widely accepted as a unified, parsimonious model of normal personality that has been validated in many different cultures and across several research settings (e.g., De Raad, 2000; Digman, 1997), with supporting studies based on many different demographic and personal characteristics of individuals (Costa \& McCrae, 1994).

The results of the Lounsbury et al. (2009) study indicated that there was a significant relationship between the five-factors of Openness, Conscientiousness, Extraversion, Agreeableness, and Neuroticism, with learner self-direction (p. 415). Their findings are important in that they further elucidate the nomological network for learner self-direction; in this case, that self-directed students displayed higher levels of Agreeableness, Conscientiousness, and Openness as well as lower levels of Neuroticism. These results also provide empirical support for self-direction in learning theorists who discuss the importance of such factors as creative achievements, new experience, and 
student participation in learning projects, intrinsic learning motivation, and self-concept (Hassan, 1982; Reynolds, 1986).

Drawing on recent developments in personality research, it is possible to extend the work of Lounsbury et al. (2009) to other personality traits that go beyond the Big Five model. Research in a number of areas has shown that validity can be enhanced above and beyond the Big Five traits by considering more narrow personality traits, which are defined as either subscales of the Big Five or as traits not encompassed by the Big Five model. For example, Lounsbury, Sundstrom, Gibson, and Loveland (2003) found that Aggression and Work Drive added substantial variance to the prediction of academic performance of middle and high school students beyond the Big Five traits. Paunonen and Nicol (2001) found that narrow traits, such as Self-Discipline, Straightforwardness, and Modesty, added significant incremental variance beyond the Big Five when predicting 12 different criteria, including grade point average, blood donations, absenteeism, and traffic violations. Also, Paunonen and Ashton (Paunonen \& Ashton, 2001) found that the NEO Personality Inventory (NEO PI-R; Costa \& McCrae, 1997) Conscientiousness-related subscales of Achievement, Self-Discipline, Competence, and Dutifulness as well as the Openness-related subscale of Ideas added significantly to the prediction of collegiate GPA above and beyond scores on the Jackson Personality Inventory (JPI-R) (Jackson, 1996) Conscientiousness scale.

\subsection{Hypotheses and Research Questions}

Previous research on broad and narrow personality traits in relation to learner self-direction has focused on either: a) bivariate correlations between the personality trait and learner self-direction; or b) the total variance in learner self-direction accounted for by Big Five or narrow traits. Because of some degree of multi-colinearity of the Big Five and narrow traits, in neither of the above cases do we know what is the unique relationship between the personality traits and learner self-direction or the unique amount of variance in learner self-direction accounted for by the personality trait. Thus, for example, we cannot say what is the unique or independent relationship between Openness and learner self-direction after controlling for the influence of the other Big Five and narrow traits in relation to learner self-direction.

To better understand how learner self-direction is related to each of the Big Five and narrow traits in their own right, without the added association or influence of the other traits, in the present study each part correlation (which has also been termed the semi-partial correlation) between each personality trait and learner self-direction after controlling for the other Big Five and narrow traits was examined. Where justifiable in terms of the empirical literature, directional hypotheses were advanced; otherwise, the trait-learner self-direction relationship was examined as a non-directional, research question. In addition, in those cases where prior results point toward a stronger relationship between the personality trait and learner self-direction, hypotheses about the relative strength of pairs of part correlations were advanced. For example, because of the strength of the bivariate relationship between Openness and learner self-direction, it is hypothesized that the part correlation between Openness and learner self-direction will be higher than the corresponding part correlations for all of the other traits examined here except Work Drive.

Below, a brief rationale for each hypothesis is provided using a twofold approach, involving: a) a deductive, construct-based approach (Barrick, Mount, \& Gupta, 2003) which specifies how the meaning of the personality trait as construct aligns with the meaning of the learner self-direction construct; and 2) basing the hypothesis on prior research relating the personality trait to learner self-direction.

\subsubsection{Big Five Traits}

\subsubsection{Hypothesis 1}

Openness will be uniquely, positively related to learner self-direction after controlling for the other Big Five and narrow traits.

\subsection{Hypothesis 1a}

The part correlation for Openness and learner self-direction will be higher than all the corresponding part correlations for the other traits except Work Drive.

Self-directed learners are motivated by new learning in a non-traditional manner, which is consistent with the construct of Openness (Costa \& McCrae, 1992). Individuals who score higher in learner self-direction would be expected to score higher in Openness since one of the main expressions of Openness is learning new material (Lounsbury \& Gibson, 2010). Also, Oddi (1984) reported a positive correlation between the OCLI and open-mindedness. In addition, Kirwan, Lounsbury, and Gibson (2010) found that Openness was the Big Five trait most highly correlated with learner self-direction $(r=.43, p<.01)$ and it was more highly correlated with learner 
self-direction than all but one of the narrow traits.

\subsubsection{Hypothesis 2}

Conscientiousness will be uniquely, positively related to learner self-direction after controlling for the other Big Five and narrow traits.

Learner self-direction requires a person to have some level of self-discipline and goal-directed behavior which is consistent with the construct of Conscientiousness (Costa \& McCrae, 1992) because the latter measures an individual's inclination "to be reliable, trustworthy, dependable, orderly, and rule-following" (Lounsbury et al., 2009, p.416). Kirwan, et al. (2010) found a significant positive correlation between Conscientiousness and learner self-direction $(r=.20, p<.01)$. Also, Oliveira \& Simões (2006) found a statistically significant relationship between Conscientiousness and learner self-direction.

\subsubsection{Hypothesis 3}

Emotional Stability (the inverse of Neuroticism) will be uniquely, positively related to learner self-direction after controlling for the other Big Five and narrow traits.

Self-directed learners who score higher on this trait are likely to have higher levels of learner self-direction because they are more focused, purposeful, as well as less distracted and emotionally reactive, than traditional learners (i.e., more teacher-directed). This relationship is understandable in that individuals who score higher on Emotional Stability tend to worry less about personal problems and insecurities and may be better able to attend to learning projects (Lounsbury et al., 2009). Indeed, several studies have confirmed a positive relationship between learner self-direction and Emotional Stability (e.g., Holmes, 2005; Lounsbury, Saudargas, \& Gibson, 2004).

\subsubsection{Hypothesis 4}

Agreeableness will be uniquely, positively related to learner self-direction after controlling for the other Big Five and narrow traits.

Self-directed learners who score high on Agreeableness are inclined to be equable, participative, helpful, cooperative, and inclined to interact with others harmoniously. By way of rationale, more agreeable individuals often strive for cooperation (Costa \& McCrae, 1992) which would facilitate self-directed learning in group settings. Self-directed learners who are lower on Agreeableness are inclined to be stubborn, argumentative, and oppositional (ibid), which could lead to lower levels of active, self-directed learning (Chen, Wang, \& Lin, 2006). In this vein, Kirwan, et al. (2010) found a modest, positive correlation between Agreeableness and learner self-direction $(r=.21, p<.01)$.

\subsubsection{Research Question 1}

What is the relationship between Extraversion and learner self-direction?

\subsubsection{Narrow Traits}

Along with the Big Five traits, two narrow traits are studied in this dissertation. Work Drive and Openness were the only narrow traits chosen as they were the only two that have been consistently statistically significant in studies involving learner self-direction (Kirwan et al., 2010; Lounsbury et al., 2009).

\subsubsection{Hypothesis 5}

Work Drive will be uniquely, positively related to learner self-direction after controlling for the other Big Five and narrow traits.

\subsection{Hypothesis 5a}

The part correlation for Work Drive and learner self-direction will be higher than all the corresponding part correlations for the other traits.

Individuals high in Work Drive are inclined to work hard and for long hours to complete projects and they are motivated to extend themselves, if necessary, to finish projects, meet deadlines, attain quotas, and achieve success (Lounsbury \& Gibson, 2010). Accordingly, students with high levels of Work Drive may have higher levels of learner self-direction because they set challenging learning goals for themselves, exert additional effort beyond normal class expectations, and extend themselves as needed to attain their learning goals (Lounsbury, Gibson, \& Hamrick, 2004). In this regard, Kirwan et al. (2010) found that Work Drive was the narrow trait most highly correlated with learner self-direction $(r=.49, p<.01)$ and was the second highest of all the traits-including narrow and Big Five traits - after Openness. 


\subsubsection{Hypothesis 6}

Optimism will be uniquely, positively related to learner self-direction after controlling for the other Big Five and narrow traits.

Individuals who are more optimistic tend to have a sanguine, hopeful outlook concerning prospects, people, and the future even in the face of difficulty and adversity. They also tend to minimize problems and persist in the face of setbacks as well as have higher levels of achievement-related dispositions (Hewitt \& gordon, 1996). This aligns well with learner self-direction which is characterized by an individual being positive and open to new possibilities as well as persisting despite obstacles to achieving learning goals. Empirical support for such a relationship can be seen in Kirwan et al.'s (2010) finding of a positive correlation between Optimism and learner self-direction $(r=.31, p$ $<.01)$.

\section{Method}

\subsection{Participant Characteristics}

Data from 1981 adult participants, age 18 and older, were used for the purposes of this study. Researchers obtained permission to conduct the study from the University of Tennessee' institutional review board. Undergraduate students $(n=1981)$ enrolled at a large southeastern state university were recruited to participate in this study. Of the 1981 participants in this study, $40 \%$ were male (60\% female). Fifty-five percent of the participants were Freshmen; $26 \%$, Sophomores; 14\%, Juniors; and 5\%, Seniors. Eighty-four percent of the participants identified themselves as Caucasian, 9\%--African-American, $2 \%$--Hispanic, 2\%--Asian, and 3\%--other. The median age of participants was 20 years old.

\subsection{Instruments}

The personality measure used in this study was the Resource Associates' Transition to College inventory (RATTC) (Lounsbury \& Gibson, 2010). The RATTC is a normal personality inventory contextualized for late adolescents (Jaffe, 1998) and adults through high school and college. It measures the Big Five Traits of Openness, Conscientiousness, Extraversion, Agreeableness, and Neuroticism. The RATTC also measures the narrow traits of Aggression, Career-Decidedness, Optimism, Self-Directed Learning, Sense of Identity, Tough-Mindedness, and Work Drive. Information pertaining to scale development, reliability, criterion-related validity, construct validity, and norming can be found in Kirwan, Lounsbury, \& Gibson (2010), Lounsbury, Levy, Park, Gibson, \& Smith (2009); Lounsbury, Tatum, et al. (2003); Lounsbury, Gibson, and Hamrick (2004); and Lounsbury \& Gibson (2010).

The Resource Associates Transition to College Inventory (RATTC) has 118 items represented by statements in which respondents are asked to express agreement or disagreement on a five-point Likert scale $(1=$ Strongly Disagree; $2=$ Disagree; $3=$ Neutral/Undecided; 4=Agree; $5=$ Strongly Agree). A brief description of the personality traits measured by RATTC involved in the present study is given below (Lounsbury \& Gibson, 2010, p.7):

1. Agreeableness - being agreeable, participative, helpful, cooperative, and inclined to interact with others harmoniously.

2. Conscientiousness - being conscientious, reliable, trustworthy, orderly, and rule following.

3. Emotional Stability - overall level of adjustment and emotional resilience in the face of stress and pressure (conceptualized as the inverse of neuroticism).

4. Extraversion - tendency to be sociable, outgoing, gregarious, warmhearted, expressive, and talkative.

5. Openness - receptivity and openness to change, innovation, new experience, and learning.

6. Optimism - having an optimistic, hopeful outlook concerning prospects, people, and the future, even in the face of difficulty and adversity as well as a tendency to minimize problems and persist in the face of setbacks.

7. Self-Directed Learning - Inclination to learn new materials and find answers to questions on one's own rather than relying on a teacher to provide answers; initiating and following through on learning without being required to for a course or prompted to by a teacher.

8. Work Drive - being hard-working, industrious, and inclined to put in long hours and much time and effort to reach goals and achieve at a high level. 


\subsubsection{The RATTC Self-Directed Learning Scale}

The Resource Associates Transition to College Self-Directed Learning scale is a 10-item scale with responses made on a five-point Likert scale: $1=$ Strongly Disagree; $2=$ Disagree; $3=$ Neutral/Undecided; $4=$ Agree; $5=$ Strongly Agree. It was developed as part of the larger Resource Associates Transitions to College Inventory, a system for measuring personality traits for adolescents and adults (Lounsbury \& Gibson, 2006). The theoretical framework for the Self-Directed Learning construct is based "directly on Brockett's (1983) conceptualization that "self-directed learning refers to activities where primary responsibility for planning, carrying out, and evaluating a learning endeavor is assumed by the individual learner" (p. 16). Table 1 contains the 10 -items comprising the RATTC Self-Directed Learning Scale

Table 1. The RATTC Self-Directed Learning Scale

\begin{aligned} & \hline Number \multicolumn{1}{c}{ Question } \\ & \hline 1. I regularly learn things on my own outside of class. \\ & 2. I am very good at finding out answers on my own for things that the teacher does not explain in class. \\ & 3. If there is something I don't understand in a class, I always find a way to learn it on my own. \\ & 4. I am good at finding the right resources to help me do well in school. \\ & 5. I view self-directed learning based on my own initiative as very important for success in school and in my \\ & future career. \\ & 6. I set my own goals for what I will learn. \\ & 8. I like to be in charge of what I learn and when I learn it. \\ & 9. I there is something I need to learn, I find a way to do so right away. \\ & 10. I am very motivated to learn on my own without having to rely on other people. \end{aligned}

(Lounsbury et al., 2009)

\subsection{Data Analysis}

Data analysis includes descriptive statistics, correlational analysis, and multiple regression analysis using the SPSS statistical package. In particular, part correlations (also known as semi-partial correlations) were analyzed to investigate the unique contribution of individual variables.

One of the problems that come up in multiple regression is that of defining the contribution of each independent variable to the multiple correlation. There are several ways of looking ways of addressing this question how much a variable contributes to the model. One answer is provided by the part correlation $s r$ and its square, $s r^{2}$.

Part correlations and squared part correlations indicate the unique variance of each independent variable in relation to the dependent variable when controlling for the unique and shared variance of the other independent variables (Cohen, Cohen, West, \& Aiken, 2003). The squared part correlation for a variable represents how much $R^{2}$ will decrease if that variable is removed from the regression equation (Pedhazur, 1997). In other words, the squared part correlation represents the proportion of variance of the dependent variable accounted for by a given independent variable above and beyond other variables.

\section{Results}

\subsection{Data Analysis-Correlations}

Pearson product-moment correlation coefficients were calculated between learner self-direction and the Big Five traits as well as narrow traits of Work Drive and Optimism. Descriptive statistics and intercorrelations among the study variables are displayed in Table 2. As can be seen in Table 2, all of the Big Five personality traits are correlated significantly and positively with learner self-direction, except for Extraversion. Specifically, in descending order of magnitude, the correlations with Self-Directed Learning were: Openness $(r=.37, p<.01)$, Emotional Stability $(r$ $=.21, p<.01)$, Agreeableness $(r=.17, p<.01)$, Conscientiousness $(r=.17, p<.01)$, Extraversion $(r=.04<.05)$, and the narrow personality traits also correlated significantly with learner self-direction, with the largest magnitude correlation observed for Work Drive $(r=.47, p<.01)$, followed by Optimism $(r=.31, p<.01)$. 
Table 2. Descriptive Statistics and Intercorrelations for the Personality Variables

\begin{tabular}{lrrrrrrrr}
\hline & $(1)$ & $(2)$ & $(3)$ & $(4)$ & $(5)$ & $(6)$ & $(7)$ & $(8)$ \\
\hline (1) Agreeableness & --- & .16 & .28 & .02 & .19 & .33 & .26 & .17 \\
(2) Conscientiousness & & --- & .13 & .06 & .05 & .23 & .33 & .17 \\
(3) Emotional Stability & & & --- & .24 & .07 & .59 & .09 & .21 \\
(4) Extraversion & & & & --- & .01 & .34 & -.01 & .04 \\
(5) Openness & & & & & --- & .18 & .41 & .37 \\
(6) Optimism & & & & & & --- & .26 & .31 \\
(7) Work Drive & & & & & & --- & .47 \\
(8) LSD & 3.74 & 3.47 & 3.17 & 3.67 & 3.57 & 4.02 & 3.18 & --.01 \\
Mean & .62 & .62 & .70 & .74 & .60 & .57 & .62 & .57 \\
Standard Deviation & & & & & & & \\
Note: $n=2102$ & & & & & \\
Correlations $>.09$ or $<-.09$ are significant at the $p<.01$ level. \\
Correlations $>.05$ and $<.09$ or $<-.05$ and $>-.09$ are significant at the $p<.05$ level. & & &
\end{tabular}

\subsection{Data Analysis-Multiple Regression}

The next phase of the analysis involved examining the part correlations of learner self-direction with Openness, Conscientiousness, Extraversion, Agreeableness, Emotional Stability, Optimism, and Work Drive. A multiple regression analysis was conducted with learner self-direction as the dependent variable, and the remaining variables as predictors entered simultaneously. The part correlations represent the correlations of learner self-direction with each of the predictor variables, independent of the other predictors. Thus, the squared part correlations give an indication of the unique contribution of each variable to learner self-direction. An examination of the squared part correlations of the five significant variables indicates that Work Drive accounted for $9.6 \%$ of the variance, Openness accounted for approximately $3.6 \%$ of the variance, Optimism accounted for $1.3 \%$ of the variance, and Extraversion and Agreeableness each accounted for less than $1 \%$ of the variance in learner self-direction.

\subsection{Analysis by Hypotheses and Research Questions}

\subsubsection{Hypothesis 1}

In order to estimate the unique relationship, or validity coefficient, between Openness and learner self-direction, a part correlation was calculated, controlling for Agreeableness, Extraversion, Conscientiousness, Emotional Stability, Optimism, and Work Drive. Openness was significantly and positively related to learner self-direction $(s r=.207, p$ $<.01$ ), supporting Hypothesis 1. Table 3 shows the part correlation and part correlation squared coefficients. An examination of the squared part correlations indicates that when all other variables were controlled for, Openness accounts for more than $3.5 \%$ of the variance in learner self-direction.

\subsubsection{Hypothesis 1a}

The part correlation for Openness $(s r=.19)$ was the second highest next to Work Drive $(s r=.30)$ supporting the hypothesis.

\subsubsection{Hypothesis 2}

In order to estimate the unique relationship, or validity coefficient, between Conscientiousness and learner self-direction, a part correlation was calculated, controlling for Agreeableness, Extraversion, Openness, Emotional Stability, Optimism, and Work Drive. Conscientiousness was positively but not significantly related to learner self-direction ( $s r=-.001, p>.05$ ), which does not support Hypothesis 2. Table 3 shows part correlation and part correlation squared coefficients. An examination of the squared part correlations indicates that when all other variables were controlled for, Conscientiousness accounts for less than .1\% of the variance in learner self-direction.

\subsubsection{Hypothesis 3}

In order to estimate the unique relationship, or validity coefficient, between Emotional Stability and learner self-direction, a part correlation was calculated, controlling for Agreeableness, Extraversion, Conscientiousness, Openness, Optimism, and Work Drive. Emotional Stability was positively and significantly related to learner self-direction $(s r=.09, p<.01)$, which supports Hypothesis 3 . Table 3 shows the part correlation and part correlation squared coefficients. An examination of the squared part correlations indicates that when all other variables were controlled for, Emotional Stability accounts for approximately $1 \%$ of the variance in learner self-direction. 


\subsubsection{Hypothesis 4}

In order to estimate the unique relationship, or validity coefficient, between Agreeableness and learner self-direction, a part correlation was calculated, controlling for Openness, Extraversion, Conscientiousness, Emotional Stability, Optimism, and Work Drive. Agreeableness was positively but not significantly related to learner self-direction ( $s r=$ $-.03, p>.05$ ), which does not support Hypothesis 4 . Table 3 part correlation and part correlation squared coefficients. An examination of the squared part correlations indicates that when all other variables were controlled for, Agreeableness accounts for less than .1\% of the variance in learner self-direction.

\subsubsection{Research question 1}

Extraversion was significantly correlated with learner self-direction $(r=.04, p<.05)$, and, the part correlation for Extraversion was significant at the .01 level ( $s r=-.07, p<.01$ ), but the variable only accounted for less than $1 \%$ of the variance in learner self-direction.

\subsubsection{Hypothesis 5}

In order to estimate the unique relationship between Work Drive and learner self-direction, a part correlation was calculated, controlling for Agreeableness, Extraversion, Conscientiousness, Emotional Stability, Optimism, and Openness. Work Drive was positively and significantly related to learner self-direction $(s r=.30, p<.01)$, which supports Hypothesis 4. Table 3 shows the part correlation and part correlation squared coefficients. An examination of the squared part correlations indicates that when all other variables were controlled for, Work Drive accounts for more approximately $10 \%$ of the variance in learner self-direction.

\subsubsection{Hypothesis 5a}

The part correlation for Work Drive $(s r=.30)$ was higher than all other corresponding part correlations.

\subsubsection{Hypothesis 6}

In order to estimate the unique relationship between Optimism and learner self-direction, a part correlation was calculated, controlling for Agreeableness, Extraversion, Conscientiousness, Emotional Stability, Openness, and Work Drive. Optimism was positively and significantly related to learner self-direction ( $s r=.12, p<.01)$, which supports Hypothesis 6. Table 3 shows the part correlation and part correlation squared coefficients. An examination of the squared part correlations indicates that when all other variables were controlled for, Optimism accounts for approximately $1.5 \%$ of the variance in learner self-direction.

Table 3. Part Correlations for Learner Self-Direction with Big Five and Narrow Traits

\begin{tabular}{lll}
\hline & $s r$ & $s r^{2}$ \\
\hline Work Drive & .30 & $.09 * *$ \\
Openness & .19 & $.04 * *$ \\
Optimism & .12 & $.01^{* *}$ \\
Emotional Stability & .09 & $.01^{* *}$ \\
Extraversion & -.07 & $.01 * *$ \\
Agreeableness & -.03 & .00 \\
Conscientiousness & -.01 & .00 \\
\hline Note: $\quad n=1981 . \quad s r=$ part correlation; $s r^{2}=$ part correlation squared. &
\end{tabular}

All variables were entered simultaneously into a multiple regression model to estimate the degree of learner self-direction prediction. The overall regression was significant, $F(7,1973)=125.66, \mathrm{p}<.01$, and these variables accounted for over $52 \%$ of the variance in learner self-direction. As can be seen in Table 4, five of the variables explained significant variance in the model: Work Drive, Openness, Optimism, Emotional Stability, and Extraversion. The strongest correlate of learner self-direction was Work Drive $(\beta=.35, p<.01)$, followed by Openness $(\beta=.37, p$ $<.01)$, Optimism $(\beta=.16, p<.01)$, Emotional Stability $(\beta=.11, p<.01)$, Extraversion $(\beta=-.08, p<.01)$, and Agreeableness $(\beta=-.04, \mathrm{~ns})$, Conscientiousness $(\beta=-.01, \mathrm{~ns})$, which had the lowest magnitude correlation with learner self-direction in the study. 
Table 4. Simultaneous Regression

\begin{tabular}{lcccccccc}
\hline & \multicolumn{2}{c}{$\begin{array}{c}\text { Unstandardized } \\
\text { Coefficients }\end{array}$} & $\begin{array}{c}\text { Standardized } \\
\text { Coeff. }\end{array}$ & \multicolumn{5}{c}{ Correlations } \\
\cline { 2 - 8 } & $\mathrm{B}$ & $\mathrm{SE}$ & $\beta$ & $t$ & Sig. & Zero-order & Partial & Part \\
\hline (Constant) & .54 & .13 & & 4.04 & .00 & & & \\
Work Drive & .40 & .03 & .35 & 15.95 & .00 & .47 & .34 & .30 \\
Openness & .24 & .02 & .21 & 10.17 & .00 & .37 & .22 & .19 \\
Optimism & .19 & .03 & .03 & 6.17 & .00 & .31 & .14 & .12 \\
Emotional Stability & .11 & .02 & .11 & 4.57 & .00 & .21 & .10 & .09 \\
Extraversion & -.07 & .02 & -.08 & -3.64 & .00 & .04 & -.08 & -.07 \\
Agree. & -.04 & .02 & -.04 & -1.77 & .08 & .17 & -.04 & -.03 \\
Conscien. & -.01 & .02 & -.01 & -.03 & .98 & .17 & -.01 & -.01 \\
\hline
\end{tabular}

\section{Discussion}

The present study was generally successful in terms of providing validation of the main research propositions. Six of the eight hypotheses were supported, which is both consistent with and extends prior studies (Kirwan et al., 2010; Lounsbury et al., 2009) in that learner self-direction was uniquely related to four of the Big Five traits studied as well as and both of the narrow traits examined here. The present findings reinforce and support Lounsbury, Levy et al.'s (2009) study which demonstrated "...the importance and richness of the self-directed learning construct and ... its role as a personality trait" (p. 417). Considering first the Big Five traits, the significant, positive relationships between them and learner self-direction are consistent with Lounsbury, Levy et al.'s (2009) findings. Regarding the narrow traits, significant, positive relationships between learner self-direction and Work Drive as well as Optimism were also supported.

In the present study, Conscientiousness was not found to have a unique, significant relationship with learner self-direction when controlling for the other traits - which does not support the second hypothesis. We failed to find evidence of a unique relationship between Conscientiousness and learner self-direction as suggested by previous research (e.g., Lounsbury et al., 2009; Oliveira \& Simões, 2006). While there was a significant bivariate correlation between Conscientiousness and learner self-direction, the part correlation was small and not significant. From a statistical standpoint, one possible explanation for this discrepancy is that Conscientiousness is multicollinear with the other traits and does not uniquely predict learner self-direction alone. However, from a learning perspective, some aspects of the global traits likely contribute to the complexity of the learner self-directed learning construct. One reason for the multicollinearity is the complexity of learner self-direction. For example, it is possible that some facets of Conscientiousness (such as competence, order, dutifulness, achievement striving, and self-discipline (Costa \& McCrae, 1992)) are important to learner self-direction (e.g., Oliveira \& Simões, 2006) and could possibly be used to enhance the level of predictability (Moon, Hollenbeck, Humphrey, \& Maue, 2003) that broader traits cannot distinguish alone. It is possible that many of these facets are expressed in narrow trait of Work Drive, which had the strongest correlation, and part correlation, with learner self-direction.

Brockett and Hiemstra (Brockett \& Hiemstra, 1991) emphasized the importance of self-directed learners being able to plan their own learning program and consistently evaluate progress. Hiemstra (1994) noted that self-directed learners should be prepared for the "unexpected" and capable of dealing with challenges in learning. Ponton and Carr (2000) state that "The concept of autonomy (Knowles, 1980; Merriam \& Caffarella, 1999) exists under the personality characteristic rubric of self-directed learning." (p. 273). A student showing initiative, resourcefulness, and persistence is exhibiting manifestations related to personality characteristics as a learner. Ponton and Carr (ibid) note that Confessore (1991, p. 129) suggests that individuals who exhibit these "conative" factors in their learning activities "possess traits which are essential to successful self-direction in learning" (p.273). These factors are related to Ponton's (1999) discussion of autonomous learning consisting of five behaviors: goal-directedness, action-orientation, active-approach to problem solving, persistence in overcoming obstacles, and self-startedness which is consistent with the afore-mentioned conceptualizations of Work Drive (Lounsbury \& Gibson, 2010). Again, this aligns with Lounsbury, Gibson et al's (2004) Work Drive construct as a predictor of performance and Gladwell's (2008) emphasis on persistence leading to success.

There are two primary limitations of the current study that should be acknowledged. First, this study was limited to participants at a single geographic area at a large, public university, leaving open the question of generalizability to other time periods, geographic areas, and types of universities. Second, most of the study participants were 
lower-level students; thus, it is not possible to know if the results would generalize to samples of primarily upper-level or graduate students.

There are a number of other interesting areas for future research which could clarify and extend the present findings. In addition to the need for replication on different samples, research could be conducted on how the Big Five and narrow personality traits relate to sense of identity and learner self-direction. Another topic for investigation is the relationship between age of students and learner self-directedness. As mentioned earlier, perhaps the most important need for future research is to utilize longitudinal research designs to help clarify the direction of causality for personality traits vis-à-vis self-directed learning and to try to determine how these linkages are established.

The results of the present study indicate that the Big Five traits as well as the two narrow traits measured in this study were each related to learner self-direction, with Work Drive and Openness accounting for most of the variance in learner self-direction on their own. Taken as a whole, the present findings were interpreted as, in part, confirming and extending the results of Lounsbury et al. (2009) and Kirwan et al. (2010) regarding the Big Five, narrow traits, and learner self-direction, demonstrating the generalizability of personality trait-learner self-direction relationships across a variety of different demographic and personal subgroups of students, and providing some clues that the direction of the causal arrow may be from personality traits to learner self-direction.

In conclusion, it is clear that learner self-direction has multiple connections to personality traits and is not clearly associated with just one of the Big Five traits. In a sense, this pattern of multiple connections to personality is consistent with the diverse factors learner self-direction has been linked to in the theoretical literature, as, for example, the six vectors of college student development that Chickering and Reisser (1993) posit as leading to identity establishment for college students. Hopefully, further research will extend and clarify the nomological network of personality traits and self-direction in learning across a broad range of settings.

\section{References}

Barrick, M., Mount, M., \& Gupta, R. (2003). Meta-analysis of the relationship between the five-factor model of personality and Holland's occupational types. Personnel Psychology, 56(1), 45-74. http://dx.doi.org/10.1111/j.1744-6570.2003.tb00143.x

Brockett, R. (1983). Self-directed learning and the hard-to-reach adult. Lifelong Learning: The Adult Years, 6(8), 16-18.

Brockett, R., \& Hiemstra, R. (1991). Self-direction in adult learning: Perspectives on theory, research, and practice. Retrieved from http://home.twcny.rr.com/hiemstra/sdlindex.html

Chen, Y., Wang, C., \& Lin, H. (2006). Explore the relationships among demography, personality traits, and self-directed learning. The Journal of Human Resource and Adult Learning, 2(2), 141-150.

Chickering, A., \& Reisser, L. (1993). Education and identity. San Francisco, CA: Jossey-Bass.

Confessore, G. J. (1991). Human behavior as a construct for assessing Guglielmino's Self-directed learning readiness scale: Pragmatism revisited. In H. B. Long \& Associates (Eds.), Self-directed learning: Consensus and conflict (pp. 123-146). Norman, OK: Oklahoma Center for Continuing Professional and Higher Education, University of Oklahoma.

Costa, P., \& Kalick, B. (2003). Assessment strategies for self-directed learning (Experts in Assessment Series). Thousand Oaks, CA: Corwin Press.

Costa, P., \& McCrae, R. (1992). Revised NEO Personality Inventory (NEO-PI-R) and NEO Five-Factor Inventory (NEO-FFI) professional manual. Odessa, FL: Psychological Assessment Services.

De Raad, B. (2000). The big five personality factors (the psycholexical approach to personality). Seattle, WA: Hogrefe \& Huber.

Digman, J. (1990). Personality structure: Emergence of the five-factor model. Annual Review of Psychology, 41, 417-440. http://dx.doi.org/10.1146/annurev.ps.41.020190.002221

Gladwell, M. (2008). Outliers: The story of success. Little, Brown and Company.

Guglielmino, L. M. (1977). Development of the Self-Directed Learning Readiness Scale. Dissertation Abstracts International, 38, 6467A.

Hamrick, F., Evans, N. J., \& Schuh, J. H. (2002). Foundations of student affairs practice. San Francisco, CA: 
Jossey-Bass.

Hassan, A. M. (1982). An investigation of the learning projects among adults of high and low readiness for self-direction in learning (Doctoral dissertation, Iowa State University, 1981). Dissertation Abstracts International, 42, 3838A.

Hewitt, P., \& Gordon, L. (1996). Personality and the coping process. In M. Zeidner \& N. Endler (Eds.), Handbook of coping: Theory, research, and applications (pp. 410-433). Oxford, UK: John Wiley \& Sons, Inc.

Hiemstra, R. (1994). Self-directed learning. Retrieved from http://home.twcny.rr.com/hiemstra/sdlhdbk.html

Holmes, A. B. (Producer). (2005). The relationship between broad and narrow personality traits and self-reported grade point average of college students. University of Tennessee Honors Thesis Projects. Retrieved from http://trace.tennessee.edu/utk_chanhonoproj/869

Jackson, D. N. (1996). Basic Personality Inventory manual (2nd ed.). London, Ontario: Sigma Assessment Systems.

Jaffe, M. L. (1998). Adolescence. New York, NY: Wiley.

Johnson, J. A., Sample, J. A., \& Jones, W. J. (1988). Self-directed learning and personality type in adult degree students. Psychology: A Journal of Human Behavior, 25(1), 32-36.

Kirwan, J. R., Lounsbury, J., \& Gibson, L. (2010). Self-directed learning and personality: The big five and narrow personality traits in relation to learner self-direction. International Journal of Self-Directed Learning, 7(2), 21-34.

Knowles, M. S. (1980). The modern practice of adult education. New York, NY: Cambridge Books.

Leitsch, P. K., \& Van Hove, S. D. (1998). Extraverted intuitives: A profile of adult learners. Psychology: A Journal of Human Behavior, 35(3-4), 44-49.

Long, H. B. (2007). Themes and theses in self-directed learning literature. International Journal of Self-Directed Learning, 4(2), 1-18.

Long, H. B., \& Redding, T. (1991). Self-directed learning dissertation abstracts. Norman, OK: Oklahoma Research Center for Continuing Professional and Higher Education, University of Oklahoma.

Lounsbury, J., \& Gibson, L. (2010). Technical manual for the Resource Associates Personal Style Inventory and Adolescent Personal Style Inventory. Knoxville, TN: Resource Associates.

Lounsbury, J., Gibson, L., \& Hamrick, F. (2004). The development of a personological measure of work drive. Journal of Business Psychology, 18, 347-371.

Lounsbury, J., Levy, J., Park, S., Gibson, L., \& Smith, R. (2009). An investigation of the construct validity of the personality trait of self-directed learning. Learning and Individual Differences, 19, 411-418. http://dx.doi.org/10.1016/j.lindif.2009.03.001

Lounsbury, J., Saudargas, R., \& Gibson, L. (2004). An investigation of Big Five and narrow personality traits in relation to intention to withdraw from college. Journal of College Student Development, 45(5), 517-534. http://dx.doi.org/10.1353/csd.2004.0059

Lounsbury, J., Tatum, H., Gibson, L., Park, S., Sundstrom, E., Hamrick, F., \& Wilburn, D. (2003). The develpment of a Big Five adolescent personality scale. Psychological Assessment, 21, 111-133.

Madison, P. (1969). Personality development during college. New York, NY: Addison-Wesley.

Merriam, S. B., \& Caffarella, R. S. (1999). Learning in adulthood. San Francisco, CA: Jossey-Bass.

Moon, H., Hollenbeck, J. R., Humphrey, S. E., \& Maue, B. (2003). The tripartite model of neuroticism and the suppression of depression and anxiety within an escalation of commitment dilemma. Journal of Personality, 71(3), 347-368. http://dx.doi.org/10.1111/1467-6494.7103004

Nakula, M. (2003). Identity and possibility. In M. Sadowski (Ed.), Adolescents at school: Perspectives on youth, identity, and education. Cambridge, MA: Harvard.

Oddi, L. F. (1984). Development and validation of an instrument to identify self-directed continuing learners. Adult Education Quarterly, 36, 97-107.

Oliveira, A. L., \& Simões, A. (2006). Impact of socio-demographic and psychological variables on the self-directedness of higher education students. International Journal of Self-Directed Learning, 3(1), 1-12. 
Paunonen, S. V., \& Ashton, M. C. (2001). Big Five factors and facets and the prediction of behavior. Journal of Personality and Social Psychology, 1(3), 524-539. http://dx.doi.org/10.1037/0022-3514.81.3.524

Paunonen, S. V., \& Nicol, A. A. (2001). The personality hierarchy and the prediction of work behaviors. In F. Hogan \& B. Roberts (Eds.), Personality psychology in the workplace (pp. 161-191). Washington, D.C.: American Psychological Association.

Ponton, M. K. (1999). The measurement of an adult's intention to exhibit personal initiative in autonomous learning. (Doctoral dissertation, The George Washington University, 1999). Dissertation Abstracts International, 60, 3933.

Ponton, M. K., \& Carr, P. B. (2000). Understanding and promoting autonomy in self-directed learning. Current Research in Social Psychology, 5(19), 271-284.

Reynolds, M. M. (1986). The self-directedness and motivational orientations of adult part-time students at a community college (Doctoral dissertation, Syracuse University, 1984). Dissertation Abstracts International, 38, 607-618.

Stockdale, S. L., \& Brockett, R. G. (2011). Development of the PRO-SDLS: A measure of self-direction in learning based on the personal responsibility orientation model. Adult Education Quarterly, 61(2), 161-180.

Waterman, A. S. (1985). Identity in the context of adolescent psychology. In A. S. Waterman (Ed.), Identity in adolescence: Process and contents (pp. 5-24). San Francisco, CA: Jossey-Bass.

Waterman, A. S. (1993). Developmental perspectives on identity formation: From adolescence to adulthood. In J. Marcia, A. Waterman, D. Matteson, S. Archer \& J. Orlofsky (Eds.), Ego identity (pp. 42-68). New York, NY: Springer-Verlag. 